\title{
Comparative study on the antimicrobial effects of essential oils from peels of three citrus fruits
}

\begin{abstract}
The use of Essential Oils as antimicrobial agents have become popular over the years in an attempt to find alternative ways of dealing with strains of bacteria that have become resistant to conventional antibiotics. This study was carried out to compare the antimicrobial effects of Citrus peel essential oils obtained from Okene Main Market, 7'33'4.39" N 6'14'9.20" E, Kogi State, Nigeria, on the clinical isolates of some microorganisms (Escherichia coli, Pseudesomonas aeruginosa, Staphylococcus aureus, and Aspergillus niger). The oils were extracted from the peels using the cold maceration method with $n$-hexane as the solvent. The agar diffusion method was used to test the susceptibility of the micro-organism strains using ciprofloxacin as the standard positive control. The experiment was carried out in duplicates and obtained data was analysed using one-way analysis of variance (ANOVA) and Duncan Multiple Range Test (DMRT), with $\mathrm{P}<0.05$ considered significant. The results revealed that Orange (Citrus sinensis) exhibited the inhibitoriest effect on the test isolates followed by lime (Citus aurantifolia) and Lemon (Citrus Limon) with the least significant effect.
\end{abstract}

Keywords: antimicrobial activities, essential oils, citrus peels
Volume 4 Issue 2 - 2019

\author{
Edogbanya PRO,' Suleiman MO,' \\ Olorunmola JB,' Oijagbe IJ ${ }^{2}$ \\ 'Department of Plant Science and Biotechnology, Kogi State \\ University, Nigeria \\ 2Department of Biology, Ahmadu Bello University, Nigeria
}

Correspondence: Edogbanya PRO, Department of Plant Science and Biotechnology, Kogi State University, Anyigba, Nigeria,Email ocholiedogbanya@gmail.com

Received: January 17, 2019 | Published: May 28, 2019

\section{Introduction}

Herbs are widely exploited in the traditional medicine and their curative potentials are well documented. ${ }^{1}$ About $61 \%$ of new drugs developed between 1981 and 2002 were based on natural products and they have been successful, especially in the areas of infectious disease and cancer. ${ }^{2}$ Recent trends however show that the discovery rate of novel chemical entities is declining. ${ }^{3}$ Natural products of higher plants may give a new source of antimicrobial agents with possibly novel mechanisms of action. ${ }^{4,5}$ The effects of plant extracts on bacteria have been studied by a very large number of researchers in different parts of the world. ${ }^{6}$ Herbal medicines have been known to man for centuries. Therapeutic efficacy of many indigenous plants for several diseases has been described by practitioners of traditional medicine. ${ }^{7}$

Essential Oils (EOs) are products obtained from plants vegetable raw materials (leaves, buds, fruits, flowers, herbs, twigs, barks, woods, roots, and seeds) ${ }^{8}$ which are complex mixtures whose composition may include volatile terpenic compounds, $\left[\left(\mathrm{C}_{5} \mathrm{H}_{8}\right) \mathrm{n}\right]$ monoterpenes $[n=2]$, sesquiterpenes $[n=3]$, diterpenes $[n=4]$ e. t. c. ${ }^{9}$ These are secondary metabolites in plants ${ }^{10}$ and responsible for the characteristic aroma in some plants (including Citrus).

Essential oils showed antimicrobial activity against a wide range of bacteria including antibiotic resistant species and fungal species. They can affect both Gram positive and Gram negative bacteria in addition to yeasts and filamentous fungi. ${ }^{11}$ The reduction of the microbial population depends on the concentrations of essential oil where high concentration of essential oil will give high antimicrobial effect and may completely inhibit the growth of micro-organisms. ${ }^{12}$ There are many methods that quantify microbiological activity of essential oils and these includes assays such as optical density, agar well diffusion, disk-diffusion and hole plate diffusion. ${ }^{13}$ The peel of Citrus fruit is a rich source of flavonoid, glycerol and volatile oils. ${ }^{14}$ Many polymethoxylated flavones have several important bioactivities which are very rare in other plants. ${ }^{15}$ Citrus essential oils have been industrially applied in many products including foods and beverages ${ }^{16}$ and their activities against some of the most important food borne pathogens have been proven. ${ }^{17}$ Since Citrus essential oils are mainly located in the fruit peels, their extraction is economically sustainable, because the fruit peel constitute a waste for the fruit juice industry. ${ }^{18}$ Citruses belonging to the family Rutaceae, are one of the main fruit crops grown throughout the world. Citrus fruits have been used by man for centuries for Agricultural, Medicine, and Herbal purposes. ${ }^{19}$ Several pharmacological properties have been attributed to various members of the Citrus species, ranging from anticancer, ${ }^{20-24}$ antifungal, ${ }^{25}$ anti-typhoid, ${ }^{23}$ anti-oxidant, ${ }^{26}$ antiulcer, ${ }^{27}$ hypolipidemic ${ }^{28}$ among others.

Resistant bacteria represent a challenge in the treatment of various well known infections and therefore necessitate the need to find new substances with antimicrobial properties to use against these micro-organisms. The harmful micro-organisms can be controlled with drugs and these results in the emergence of multiple drugresistant bacteria and it has created alarming clinical situations in the treatment of infections. The significance of this work is to determine the antimicrobial and inhibitory effect of three different species of Citrus peel essential oils and compare to determine the most effective based on the facts that grounds of medical pharmacology have been constructed by herbal remedies for ages and have formed basis for traditional medicine as natural antimicrobial agents (agents that kill or inhibit the growth of other micro-organisms) have potential benefits over synthetic antimicrobials ${ }^{29}$ and have received popularity from a series of micro-organisms control related issues and also as a source of pharmaceutical active compound ${ }^{30}$ which is not only cheap but safe and with no side effects. ${ }^{31}$

The aim of this research is to carry out a comparative study of the antimicrobial effect of the essential oils of the peels of three Citrus fruits (Orange, Lemon and Lime) on micro-organisms. 


\section{Materials and methods \\ Collection of plant materials}

The Citrus fruits used in this study were obtained from the okene main market, 7'33'4.39" N 6'14'9.20" E Kogi State, Nigeria and was confirmed at the department of Biological Sciences. It was washed with de-ionized water, peeled, and cut into smaller pieces which were then taken to the laboratory of the department of Biochemistry, K.S.U. Anyigba, Kogi State and oven dried at $70^{\circ} \mathrm{C}$ for two days until required for analysis.

\section{Extraction of oil from plant materials}

Chemical used in this study (n-hexane) was of reagent grade and were sought from the same department as mentioned above where the extraction was executed. The cold maceration method was adopted in extracting the essential oils by the use of n-hexane as described by A. OA. C, (2000) and the percentage oil yield was determined. Oven dried Citrus peels samples of 96.5grams of orange, 120.0grams of lemon and 78.56grams of lime were weighed and wrapped in a paper towel separately, and each sample was soaked separately in an air-tight container using $\mathrm{n}$-hexane (boiling point $65^{\circ} \mathrm{C}$ ) for a period of twenty-four hours. The extracts were concentrated after twentyfour hours using the rotary evaporator. The oil content was weighed to determine the density of the oil and the percentage oil yield was obtained by expressing the oil weight as a percentage of the sample.

$$
\begin{array}{ccc}
\% & \text { oilyield }= & (\text { weightofsample+papertowel)- } \\
(\text { weightofsample+papertowel) } & \times 100 / \text { weight of sample }
\end{array}
$$

Isolates of bacteria and fungi was obtained from the department of Microbiology Kogi State University, Kogi State, Nigeria.

\section{Sterilization of materials}

Sterilization of the glass wares used was done by autoclaving at $121^{\circ} \mathrm{C}$ for 15 minutes. The heat liable materials were also autoclaved at same temperature for a period of 8 minutes.

\section{Sterilization of culture media}

The culture media used which include; Mueller Hinton's agar and peptone water were prepared according to the manufacturer's instruction and autoclaved at $121^{\circ} \mathrm{C}$ for 15 minutes. The workbench was continuously kept in a sterilized condition by swiping with Methylated Spirit.

\section{Test micro-organisms and growth media}

The following bacterial strains Staphylococcus aureus, Escherichia coli, and Pseudomonas aeruginosa and fungal strain Aspergillus Niger, were chosen based on their clinical and pharmacological importance. The bacterial strains which were obtained from the Department of Micro-Biology, Kogi State University, Anyigba was used for evaluating the antimicrobial activity of the extracted essential oils. The bacterial and fungal stock cultures were revived using peptone water and incubated for 24 hours at $37^{\circ} \mathrm{C}$ following refrigeration storage at $4^{\circ} \mathrm{C}$. The bacterial and fungal strains were grown in Mueller-Hinton agar (MHA) plates at $37^{\circ} \mathrm{C}$ and the stock cultures were maintained at $4^{\circ} \mathrm{C}$.

\section{Antimicrobial bioassay}

In vitro antibacterial and antifungal activities of plant part (Citrus fruits peels essential oils) against three pathogenic bacteria (two Gram-positive and negative) and a pathogenic fungi (Aspergillus niger) were investigated by the agar diffusion method..$^{32}$ Antimicrobial activity testing was carried out by using agar diffusion method. A set of three dilutions $(90,60$, and $30 \%)$ of the Citrus fruits peels extracts were prepared by diluting in a diluent of $0.5 \%$ tween 20 , and $0.5 \%$ DMSO made up to $100 \mathrm{ml}$ by distilled water. Mueller-Hinton sterile agar plates were flooded with $2 \mathrm{ml}$ indicator microbial stains $\left(10^{8}\right.$ cfu) (Escherichia coli, Pseudomonas aeruginosa, Staphylococcus aureus, Aspergillus Niger), and the excess drained. A cork borer was flamed and used to bore five wells which contained the treatments $0.5 \%$ tween and $0.5 \%$ DMSO (negative control), 30, 60, and $90 \%$ (extracts), and $0.5 \%$ Ciprofloxacin (positive control) and allowed to stay at $37^{\circ} \mathrm{C}$ for 3 hours. The zones of growth inhibition around the disks were measured using venier caliper and a meter rule after 18 to 24hours of the incubation at $37^{\circ} \mathrm{C}$ for bacteria and 48 to 96 hours for fungi at $28^{\circ} \mathrm{C}$. The experiments were done in duplicates.

\section{Statistical analysis}

One way Analysis of Variance (ANOVA) was used to compare the mean inhibition zones of the different treatment groups and Duncan Multiple Range Test (DMRT) was used to separate means where significant. $\mathrm{P}<0.05$ was considered significant.

\section{Results}

After extraction, $20.0 \mathrm{ml}, 22.5 \mathrm{ml}$, and $20.0 \mathrm{ml}$ of essential oil were obtained from the orange, lemon, and lime peels with a density of $0.67,0.7$, and 0.76 respectively (Table 1 ). The sensory evaluation revealed them to be watery in viscosity, orange, dark green and light green in colour respectively with a pungent smell.

\section{Antimicrobial test}

Effect of various extracts on different isolates: The lemon peel essential oil extract had no significant effect $(\mathrm{p}>0.05)$ on all the bacterial isolates (Escherichia coli, Pseudomonas aeruginosa, Staphylococcus aureus.) except on Aspergillus Niger at 30\% concentration, when compared to the positive control (Table 2).

The lime peel oil extract had a significant effect $(\mathrm{p}<0.05)$ on Pseudomonas aeruginosa, Staphylococcus aureus and Aspergillus Niger but had little significant effect on Escherichia coli. For Pseudomonas aeruginosa, the zone of inhibition increases significantly $(\mathrm{p}<0.05)$ from $6.00 \mathrm{~mm}$ to $20.00 \mathrm{~mm}$ as the concentration of oil extract increased from $0-90 \%$. The zone of inhibition for Staphylococcus aureus also increased significantly $(\mathrm{p}<0.05)$ from $0.00 \mathrm{~mm}$ to $28.50 \mathrm{~mm}$ as the concentration of oil extract increased from $0-90 \%$ and same for Aspergillus niger which increases from $6.00 \mathrm{~mm}$ to $25.75 \mathrm{~mm}$. The lime extract only proved effective on Escherichia coli at $90 \%$ concentration. There was no significant difference $(\mathrm{p}>0.05)$ between the zone of inhibition at $90 \%$ and the positive control $(0.5 \%$ ciprofloxacin) (i.e. at $90 \%$ the extract competed favorably with the ciprofloxacin) (Table 3).

The orange peel oil extract had significant effect on all the test isolates. The zone of inhibition of Escherichia coli increased significantly $(\mathrm{p}<0.05)$ from $6.00 \mathrm{~mm}$ to $5.50 \mathrm{~mm}$, Pseudomonas aeruginosa from $8.50 \mathrm{~mm}$ to $21.00 \mathrm{~mm}$ and the zone of inhibition for Staphylococcus aureus also increased significantly $(\mathrm{p}<0.05)$ from $13.75 \mathrm{~mm}$ to $19.00 \mathrm{~mm}$ as the concentration of oil extract increased from $0-90 \%$. The fungal strain Aspergillus Niger was only affected by 
the extract at higher concentrations of $90 \%$ with a zone of $17.50 \mathrm{~mm}$. There was no significant difference $(\mathrm{p}>0.05)$ between the zone of inhibition at $60 \%, 90 \%$ and the positive control ( $0.5 \%$ ciprofloxacin) (at $60 \%$ the extract competed favorably with the ciprofloxacin which is a standard drug) (Table 4).

Comparative effects of lemon, lime and orange peel oil extracts at different concentrations on various isolates: The results revealed that only the orange extract at $60 \%$ had a significant effect $(\mathrm{p}<0.05)$ on Escherichia coli with zones of inhibition of $13.25 \mathrm{~mm}$ (Table 5).

At $30 \%$ there was no significant difference in the effects of all three extracts on Pseudomonas aeruginosa. At $60 \%$ only the lime extract had a significant effect $(\mathrm{p}<0.05)$ on Pseudomonas aeruginosa with an inhibition zone of $14.50 \mathrm{~mm}$. At $90 \%$ the lemon extract had the highest significant effect on Pseudomonas aeruginosa with a zone of inhibition of $14.50 \mathrm{~mm}$, while there was no significant difference Table I Quantity and density of essential oil extracted from the citrus peels $(p<0.05)$ in the effects of lime and orange extracts (Table 6).

At $30 \%$ only the orange extract had a significant $(\mathrm{p}<0.05)$ effect on Staphylococcus aureus. At $60 \%$ the orange extract had the highest significant effect $(\mathrm{p}<0.05)$ on Staphylococcus aureus with a zone of inhibition of $22.25 \mathrm{~mm}$, followed by that of lime extract $(7.50 \mathrm{~mm})$, while that of lemon extract had no significant ( $>>0.05$ ) effect. At $90 \%$ the lime extract had the highest significant $(\mathrm{p}<0.05)$ effect with a zone of inhibition of $26.50 \mathrm{~mm}$, followed by that of orange $(19.00 \mathrm{~mm})$, while that of lemon extract had no significant effect $(\mathrm{p}>0.05)$ (Table 7).

At 30 and $60 \%$ there were no significant differences in the effects of the three extracts on Aspergillus Niger. At the concentration of $90 \%$ the lime and orange extracts had a significant effect on Aspergillus niger with inhibition zones of $25.75 \mathrm{~mm}$ and $17.50 \mathrm{~mm}$ respectively, but there was no significant difference between them (Table 8).

\begin{tabular}{llllll}
\hline Plant material & Weight $(\mathbf{g m}$.) & Volume of $\mathbf{n}$-hexane & \%oil yield & Volume of oil $(\mathbf{m l})$ & Density \\
\hline Orange peel & $9675 \%$ & $50000 \%$ & $1168 \%$ & $2000 \%$ & 0.67 \\
Lemon peel & 120.01 & 500 & 11.2 & 22.5 & 0.7 \\
Lime peel & 78.56 & 500 & 13.21 & 20 & 0.76 \\
\hline
\end{tabular}

Table 2 Effect of oil extract of lemon peel on various strains of isolates

\begin{tabular}{|c|c|c|c|c|}
\hline \multirow{2}{*}{$\begin{array}{l}\text { Treatment } \\
\text { (\%v/v) }\end{array}$} & \multicolumn{4}{|c|}{ Zone of Inhibition (mm) } \\
\hline & E.C & P.A & S.A & A.N \\
\hline A & $0.00 \pm 0.00 \mathrm{a}$ & $0.00 \pm 0.00 \mathrm{a}$ & $0.00 \pm 0.00 \mathrm{a}$ & $0.00 \pm 0.00 \mathrm{a}$ \\
\hline B & $0.00 \pm 0.00 \mathrm{a}$ & $0.00 \pm 0.00 \mathrm{a}$ & $0.00 \pm 0.00 a$ & $7.00 \pm 7.00 \mathrm{a}$ \\
\hline C & $0.00 \pm 0.00 \mathrm{a}$ & $0.00 \pm 0.00 \mathrm{a}$ & $0.00 \pm 0.00 \mathrm{a}$ & $0.00 \pm 0.00 \mathrm{a}$ \\
\hline
\end{tabular}

$n=3$; values with same superscript down the column are not significantly different $(p>0.05)$

KEY:A=Negative control (0.05\% DMSO and 0.05\% tween 20); B=30\% extract; $C=60 \%$ extract; $D=90 \%$ extract; $E=0.5 \%$ Ciprofloxacin; $E$. C, Escherichia coli; P.A, Pseudomonas aeruginosa; S.A, Staphylococcus aureus;A.N, Aspergillus Niger

Table 3 Effect of oil extract of lime peel on various strains of isolates

\begin{tabular}{lllll}
\hline Treatment(\% v/v) & \multicolumn{2}{l}{ Zone of Inhibition $(\mathbf{m m})$} & \\
& E.C & P.A & S.A & A.N \\
\hline A & $0.00 \pm 0.00 \mathrm{a}$ & $0.00 \pm 0.00 \mathrm{a}$ & $0.00 \pm 0.00 \mathrm{a}$ & $0.00 \pm 0.00 \mathrm{a}$ \\
B & $0.00 \pm 0.00 \mathrm{a}$ & $6.00 \pm 6.00 \mathrm{ab}$ & $0.00 \pm 0.00 \mathrm{a}$ & $6.00 \pm 6.00 \mathrm{a}$ \\
C & $0.00 \pm 0.00 \mathrm{a}$ & $14.50 \pm 2.50 \mathrm{bc}$ & $7.50 \pm 7.50 \mathrm{ab}$ & $11.25 \pm 11.25 \mathrm{a}$ \\
\hline
\end{tabular}

$n=3$; values with same superscript down the column are not significantly different $(p>0.05)$

KEY:A=Negative control (0.05\% DMSO and 0.05\% tween 20); $B=30 \%$ extract; $C=60 \%$ extract; $D=90 \%$ extract; $E=0.5 \%$ Ciprofloxacin; $E . C$, Escherichia coli; P.A, Pseudomonas aeruginosa; S.A, Staphylococcus aureus;A.N, Aspergillus Niger 
Table 4 Effect of oil extract of orange peel on various strains of isolates.

\begin{tabular}{lllll}
\hline Treatment(\% v/v) & \multicolumn{4}{l}{ Zone of Inhibition $(\mathbf{m m})$} \\
\hline & E.C & P.A & S.A & A.N \\
\hline B & $0.00 \pm 0.00 \mathrm{a}$ & $0.00 \pm 0.00 \mathrm{a}$ & $0.00 \pm 0.00 \mathrm{a}$ & $0.00 \pm 0.00 \mathrm{a}$ \\
C & $6.00 \pm 6.00 \mathrm{a}$ & $8.50 \pm 8.50 \mathrm{a}$ & $13.75 \pm 1.25 \mathrm{~b}$ & $0.00 \pm 0.00 \mathrm{a}$ \\
& $13.25 \pm 1.75 \mathrm{ab}$ & $8.25 \pm 8.25 \mathrm{a}$ & $22.25 \pm 1.25 \mathrm{c}$ & $0.00 \pm 0.00 \mathrm{a}$ \\
\hline
\end{tabular}

$n=3$; values with same superscript down the column are not significantly different $(p>0.05)$

KEY: $A=$ Negative control (0.05\% DMSO and 0.05\% tween 20); B=30\% extract; $C=60 \%$ extract; $D=90 \%$ extract; $E=0.5 \%$ Ciprofloxacin; E.C, Escherichia coli; P.A, Pseudomonas aeruginosa; S.A, Staphylococcus aureus;A.N, Aspergillus Niger

Table 5 Comparative effect of oil extract of lemon, lime and orange peel on Escherichia .coli at different concentration

\begin{tabular}{lllll}
\hline Extract & \multicolumn{4}{l}{ Zone of inhibition $(\mathbf{m m})$} \\
& $0 \%$ & $30 \%$ & $60 \%$ & $90 \%$ \\
\hline Lemon & $0.00 \pm 0.00 \mathrm{a}$ & $0.00 \pm 0.00 \mathrm{a}$ & $0.00 \pm 0.00 \mathrm{a}$ & $10.00 \pm 10.00 \mathrm{a}$ \\
Lime & $0.00 \pm 0.00 \mathrm{a}$ & $0.00 \pm 0.00 \mathrm{a}$ & $0.00 \pm 0.00 \mathrm{a}$ & $0.00 \pm 0.00 \mathrm{a}$ \\
Orange & $0.00 \pm 0.00 \mathrm{a}$ & $6.00 \pm 6.00 \mathrm{a}$ & $13.25 \pm 6.00 \mathrm{~b}$ & $5.50 \pm 5.50 \mathrm{a}$ \\
\hline
\end{tabular}

$n=3$; values with same superscript down the column are not significantly different $(p>0.05)$

Table 6 Comparative effect of oil extract of lemon, lime and orange on Pseudomonas aeruginosa at different concentrations

\begin{tabular}{lllll}
\hline Extract & \multicolumn{4}{l}{ Zone of inhibition $(\mathbf{m m})$} \\
\hline & $0 \%$ & $30 \%$ & $60 \%$ & $90 \%$ \\
\hline Lemon & $0.00 \pm 0.00 \mathrm{a}$ & $0.00 \pm 0.00 \mathrm{a}$ & $0.00 \pm 0.00 \mathrm{a}$ & $0.00 \pm 0.00 \mathrm{a}$ \\
Lime & $0.00 \pm 0.00 \mathrm{a}$ & $6.00 \pm 6.00 \mathrm{a}$ & $14.50 \pm 2.50 \mathrm{~b}$ & $20.00 \pm 0.00 \mathrm{~b}$ \\
Orange & $0.00 \pm 0.00 \mathrm{a}$ & $8.50 \pm 8.50 \mathrm{a}$ & $8.25 \pm 8.25 \mathrm{a}$ & $21.00 \pm 1.00 \mathrm{~b}$ \\
\hline
\end{tabular}

$n=3$; values with same superscript down the column are not significantly different $(p>0.05)$

Table 7 Comparative effect of oil extracts of lemon, lime and orange on Staphylococcus aureus at different concentration

\begin{tabular}{lllll}
\hline Extract & \multicolumn{4}{l}{ Zone of inhibition $(\mathbf{m m})$} \\
\hline & $0 \%$ & $30 \%$ & $60 \%$ & $90 \%$ \\
\hline Lemon & $0.00 \pm 0.00 \mathrm{a}$ & $0.00 \pm 0.00 \mathrm{a}$ & $0.00 \pm 0.00 \mathrm{a}$ & $0.00 \pm 0.00 \mathrm{a}$ \\
Lime & $0.00 \pm 0.00 \mathrm{a}$ & $0.00 \pm 0.00 \mathrm{a}$ & $7.50 \pm 7.50 \mathrm{ab}$ & $26.50 \pm 8.50 \mathrm{~b}$ \\
Orange & $0.00 \pm 0.00 \mathrm{a}$ & $13.75 \pm 1.25 \mathrm{~b}$ & $22.25 \pm 1.25 \mathrm{~b}$ & $19.00 \pm 2.50 \mathrm{ab}$ \\
\hline
\end{tabular}

$\mathrm{n}=3$; values with same superscript down the column are not significantly different $(\mathrm{p}>0.05)$

Table 8 Comparative effect of oil extracts of lemon, lime and orange on Aspergillus Niger at different concentrations

\begin{tabular}{lllll}
\hline Extract & \multicolumn{4}{l}{ Zone of inhibition $(\mathbf{m m})$} \\
\hline Lemon & $0 \%$ & $30 \%$ & $60 \%$ & $90 \%$ \\
Lime & $0.00 \pm 0.00 \mathrm{a}$ & $7.00 \pm 7.00 \mathrm{a}$ & $0.00 \pm 0.00 \mathrm{a}$ & $0.00 \pm 0.00 \mathrm{a}$ \\
Orange & $0.00 \pm 0.00 \mathrm{a}$ & $0.00 \pm 0.00 \mathrm{a}$ & $12.50 \pm 12.50 \mathrm{a}$ & $17.50 \pm 2.50 \mathrm{~b}$ \\
\hline
\end{tabular}

$\mathrm{n}=3$; values with same superscript down the column are not significantly different $(\mathrm{p}>0.05)$ 


\section{Discussion}

The finding of this research contradicts a similar work by Kamal $\mathrm{S}^{33}$ who reported that among the Citrus species tested, Citrus sinensis has the highest percentage oil yield followed by Citrus reticulate and Citrus paradisii respectively compared to this research in which Citrus aurantifolia has the maximum oil yield despite it been the least quantity wise followed by Citrus sinensis and Citrus limon respectively. This difference could be attributed to the method of extraction employed as ${ }^{33}$ made use of the Soxhlet extraction method and this research made use of the cold maceration method.

By comparison of the antimicrobial effects of the three Citrus species essential oil extracts, orange extract proved to be the most effective against the tested microorganisms followed by Lime while lemon turned out to be the least effective as it exhibited no significant effect on all the isolates. The Orange peel extract exhibited effect on all three bacterial isolates (Escherichia coli, Pseudomonas aeruginosa and Staphylococcus aureus) at the three different concentrations. It also proved effective against Aspergillus Niger at 60 and 90\%. The effectiveness of the extract increased with an increase in its concentration. The lime extract had effect on both Pseudomonas aeruginosa and Aspergillus Niger at the three different concentrations (30,60 and 90\%) and Staphylococcus aureus at 60 and 90\% with a little effect on Eschericha coli (a stubborn and more resistant bacteria). The Lemon extract was only effective on Aspergillus Niger at $30 \%$ and ineffective at an increased concentration. It exhibited no effect on any of the bacterial strains at all. It was observed that the antimicrobial activities of the essential oils generally increased with an increase in their concentrations.

At all three concentrations, orange peel essential oil proved effective against Escherichia coli while lemon was only effective against it at $90 \%$ and Lime peel essential oil completely ineffective at all concentrations.

At all three concentrations, Orange and Lime exhibited significant effects on Pseudomonas aeruginosa with orange being the most effective at 30 and $90 \%$ and lime at $60 \%$. Pseudomonas aeruginosa was completely resistant against Lemon peel essential oil at all concentrations.

The orange peel essential oil proved to be the best against Staphylococcus aureus as it was effective at all three concentrations $(30,60$, and $90 \%)$ while Lime was effective at higher concentrations of 60 and $90 \%$ and Lemon peel essential oil was completely resisted by Staphylococcus aureus at all concentrations.

Aspergillus Niger was inhibited most by lime peel essential oil compared to others. The Lime extract was effective at all three concentrations followed by Orange at 60 and $90 \%$ and Lemon at 30\% only.

This work contradicts a similar work by Shalu $\mathrm{H}^{34}$ who reported that Lemon peel oil showed the most inhibitory effect than orange and lime with a recorded inhibitory effect on Candida alibican by the three essential oils but in total support of the work of ${ }^{35}$ which reported that orange peel oil is more effective as an antibacterial agent than Lemon peel oil. The discrepancy in result could be as a result of difference in the environmental conditions of the different location source as clearly reported by Ozcan $\mathrm{M}^{36}$ that location causes variation in the chemical composition of essential oils as the plant samples used in this work were gotten from the Okene main Market,
7'33'4.39" N 6'14'9.20" E Okene, Kogi State, Nigeria while that of ${ }^{37}$ was from Mumbai, India. The method of extraction is another factor to consider also $\mathrm{as}^{37}$ made use of hydrodistillation method while the cold maceration method with n-hexane was employed in this work.

The reason for the different sensitivity of the Gram negative bacteria (Escherichia coli and Pseudomonas aeruginosa) compared to that of Gram positive (Staphylococcus aureus) could be due to differences in their cell wall composition as the later possess an outer peptidoglycan layer which act as a permeability barrier whereas the former have an outer membrane. ${ }^{38}$ The inhibitory activity of the essential oil may be a cumulative effect of D-Limonene and some other unidentified components or flavonoids and phenolic compound present. ${ }^{39}$ For instance, Flavonoids are known as antimicrobial agents and some phenolic compounds have been shown to inhibit the growth of Staphylococcus aureus. ${ }^{40}$

\section{Conclusion}

From this research, it can be concluded that lemon (Citrus limon) peel essential oil has the least or no antimicrobial effect on the four microorganisms test isolate while orange (Citrus sinensis) peel essential oil proved to be the most effective against the tested microorganisms isolate, followed by Lime (Citrus aurantifolia). The citrus fruit peels essential oils could be seen to have more inhibitory effect on bacterial strains compared to the fungal strain.

Citrus peels wastes needing urgent disposal to avert health hazards from environmental pollution should be harnessed to generate industrial raw materials with great potential for stimulating industrial, economic growth, employment generation and national wealth.

Citrus peel essential oils should be employed as an alternative to synthetic preservatives to minimize their ill effects as they are natural and protect human health.

\section{Acknowledgments}

None

\section{Conflicts of interest}

Author declares there is no conflict of interest.

\section{References}

1. Dubey NK, Kumar R, Tripathi P. Global promotion of herbal medicines: India's opportunity. Current Science Association. 2004;86(1):37-41.

2. Cragg GM, Newman DJ. Biodiversity: A continuing source of novel drug leads. Pure Appl. Chem. 2005;77(1):7-24.

3. Lam KS. New aspects of Natural products in drug discovery. Trends Microbiol. 2007;15:279-289.

4. Shahidi BH. Evaluation of antibacterial properties of Iranian medicinalplants against Micrococcus luteus, Serratia morcescens, Klebsiella pneumonia, and Bordetella bronchoseptica. Asian Journal of Plant Science. 2004;3(1):82-86.

5. Runyoro DK, Matee MI, Ngassapa OD, et al. Screening of Tanzanian medicinal plants for anti-candida activity. BMC Complement Altern Med. 2006;6:11.

6. Reddy PS, Jamil K, Mashusudhan P, et al. Antibacterial activity of isolates from piper longum and Taxus baccata. Pharmaceutical Biology. 2001;39(3):236-238 
7. Ramasamy S, Charles MA. Antibacterial effect of volatile components of selected medicinal plants against human pathogens. Asian Journal of Microbiology, Biotechnology \& Environmental Sciences Paper. 2004;6(2):209-210.

8. Berger RG. Flavours and fragrance: chemistry, bioprocessing and sustainability. 2007;118-133, 329.

9. Smith DC, Forland S, Bachnos E, et al. Qualitative analysis of citrus fruit extracts by GC/MS; an undergraduate experiment. The chemical educator. $2001 ; 6(1): 28-31$.

10. Mazen KT. Molecular regulation of plant monoterpene bio synthesis in relation to fragrance. wageningan University, Netherlands. 2002.

11. Soni S, Soni UN. In-vitro antibacterial and antifungal activity of selected essential oils. International Journal of Pharmaceutical Science. 2014;6:586-596

12. Kalemba D, Kunicka A. Antibacterial and antifungal properties of essentia oils. Curr Med Chem. 2003;10(10):813-829.

13. Burt S. Essential oils: their antibacterial properties and potential applications in foods--A review. Int J Food Microbiol. 2004;94(3):223253.

14. Shahnah S, Ali M, Ansari SH, et al. A New sesquiterpene derivative from fruit peel of citrus limon (Linn.) Burm f. Food Science Pharmacology. 2007;75:165-170

15. Ahmad MM, Salim-ur-Rehman, Iqbal Z, et al. Genetic variability of essential oil composition in four citrus fruits species. Pak. J. Bot. 2006;38(2):319-324.

16. Kotzekidou P, Giannakidis P, Boulamatsis A. Antimicrobial activity of some plant extracts and essential oils against foodborne pathogens invitro and on the fate of inoculated pathogens in chocolate. Food Science Technology. 2007;41:119-127.

17. Settanni L, Palazzolo E, Gurrasi V, et al. Inhibition of food-borne pathogen bacteria by essential oils extracted from citrus fruits cultivated in China Food Control. 2012;26(2):326-330.

18. Boukroufa M, Bautekedjiret C, Petigny L, et al. Bio-refinery of orange peels waste: a new concept based on integrated green and solvent free extraction processes using ultra-sound and microwave techniques to obtain essential oil, polyphenols, and pectin. Ultrason Sonochem. 2015;24:72-79.

19. Tomar A, Mall M, Rai P. Pharmacological importance of citrus fruits International Journal of Pharmaceutical Science and Research 2013;4(1):156-160.

20. Jacob R, Hasegawa S, Manners G. The potential of citrus limonoids as anticancer agents. Perishables handling quarterly. 2000;102:6-8.

21. Silalahi J. Anticancer and health protective properties of citrus fruit components. Asia Pac J Clin Nutr. 2002;11(1):79-84.

22. Enterazi M, Majid A, Falahian F, et al. Antimutagenic and anti-cancer effects of citrus medica fruit juice. Acta Med Iron. 2009;47(5):373-377.

23. Kumar KA, Narayani M, Subanthini A, et al. Antimicrobial activity and phytochemical analysis of citrus fruit peels-utilization of fruit waste. International Journal of Engineering Science and Technology. 2011;3(6):5414-5421.

24. Lawal HO, Adewuyi GO, Fawehinmi AB, et al. Bioassay of herbal mosquito repellant formulated from the essential oils of plants. Journal of Natural Products. 2012;5:109-115.

25. Valezquez-Nunez MJ, Avila-Sosa R, Palou E, et al. Antifungal activity of orange peel essential oil applied directly or vapour contact. Food Control. 2013;3(1):1-4.

26. Duda-Chodak A, Tarko T. Antioxidant properties of different fruits seeds and peels. Acta Sci Pol Technol. 2007;6(3):29-36.

27. Nagaraju B, Anand SC, Ahmed N, et al. Antiulcer activity of extracts of citrus medica Linn. Fruit against ethanol-induced ulcer in rats. Advances in Biological Research. 2012;6(1):24-29.

28. Khan Y, Khan RA, Syeda, et al. Evaluation of hypolipidemic effect of citrus lemon. Journal of Basic and Applied Sciences. 2010;6(1):39-43.

29. Tagoe D, Baidoo S, Dadzie I, et al. A comparison of the antimicrobial (antifungal) properties of garlic, ginger and lime on Aspergillus flavus, Aspergillus niger and Cladosporium herbarium using organic and water base extraction methods. The Internet Journal of Tropical Medicine. 2010;7(1).

30. Amrita V, Sonal D, Shalini R. Antibacterial effect of Herbs and Spices Extract on Escherichia coli. Electronic Journal of Biology. 2009;5(2):40 44.

31. Chanthaphon S, Chanthachum S, Hongpattarakere T. Antimicrobial activities of essential oil and crude extracts from Matricaria pubescens. Journal of Medicinal Plant Research. 2008;6(16):3124-3128.

32. Alzoreky NS, Nakahara K. Antibacterial activity of extracts from some edible plants commonly consumed in Asia. Int J Food Microbiol. 2003;80(3):223-230.

33. Kamal S, Manmohan S, Birenda S. A review on chemical and medicobiologicalapplications of Jatropha curcas. International Research Journal of Pharmacy. 2011;2:61-66.

34. Shalu H, Geeta I, Ashok W. Antimicrobial activity of Citrus sinensis (Orange), Citrus limetta (sweet lime) and Citrus limon (Lemon) peel on selected food borne pathogens. International Journal of Life Science Research. 2015;3:35-39.

35. Subba MS, Somithri TC, Suryanarayana RAO. Antioxidant and antibacterial activities of Nephelium lappaceum I. Extracts. Food Science Technology. 2008;46:2029-2035.

36. Ozcan M, Chalchat JC. Effect of different locations on the chemical composition of essential oils of laurel (Laurus nobilis L.) leaves growing wild in Turkey. J Med Food. 2005;8(3):408-411.

37. Choudum SA, Shalu MA. The class of $\{3 \mathrm{~K} 1, \mathrm{C} 4\}$-free graphs. Australian Journal of Combinatorics. 2005;32 (32):111-116.

38. Samarakoon K, Seneviranthne M, Lee WW, et al. Antibacterial effect of Citrus press-cakes dried by high speed and far-infrared radiation drying method. Nutr Res Pract. 2012;6(3):187-194.

39. Unal MU, Ucan F, Sener A, et al. Research on Antifungal and Inhibitory Effects of DL-Limonene on Some Yeasts. Turkish Journal of Agricultural and Forestry. 2012;36(5): 576-582.

40. Cushnie TP, Lamb AJ. Antimicrobial Activity of Flavonoids. Int $J$ Antimicrob Agents. 2005;26(5):343-356. 